\title{
DESAFIOS DA ATUAÇÃO DO FISIOTERAPEUTA NO APOIO MATRICIAL À ATENÇÃO BÁSICA: UMA ANÁLISE DADEMANDA
}

\author{
CHALLENGES OF THE PHYSIOTHERAPIST \\ PERFORMANCE IN THE MATRIX SUPPORT TO \\ PRIMARY CARE: AN ANALYSIS OF DEMAND
}

Larissa Bragagnolo (ORCID: 0000-0002-6643-8465) ${ }^{1}$

Giovani Gurgel Aciole (ORCID: 0000-0002-6400-8293)2

Autor Correspondente Giovanni Gurgel Aciole E-mail: giovanni.aciole@gmail.com

\section{RESUMO}

Os conceitos de apoio matricial e equipe de referência foram incorporados à política de saúde para potencializar a integralidade do cuidado, ampliando a prática clínica e o diálogo entre os trabalhadores de saúde. Neste texto, relata-se uma experiência do fisioterapeuta no apoio matricial à Atenção Básica, na qual este profissional é predominantemente acionado por queixas de dores musculoesqueléticas, os encaminhamentos são realizados de maneira informal, e o apoiador é visto como profissional que ajuda a dar conta da demanda. Sob esse olhar, evidenciam-se aspectos a serem superados pelo apoio matricial como estratégia do trabalho em saúde, para que sua consolidação atinja a articulação entre equipe e apoiadores na forma sugerida pela proposta do Ministério da Saúde.

Palavras-chave: Fisioterapia; Atenção Primária à Saúde; Integralidade em Saúde; Saúde Pública.

\begin{abstract}
The concepts of matrix support and reference team were incorporated into health policy to potentialize the comprehensiveness of care, enhancing clinical practice and dialogue between the health workers. This paper reports an experience of the physiotherapist in the matrix support to primary care, in which this work is predominantly triggered by complaints of musculoskeletal pain, referrals are made informally, and is seen as supportive professional help to cope with the demand. From this perspective, aspects to be overcome by matrix support as a health care work strategy are evidenced, so that its consolidation reaches the articulation between the team and supporters in the manner suggested by the proposal of the Ministry of Health.
\end{abstract}

Keywords: Physical Therapy; Primary Health Care; Integrality in Health; Public health.
${ }^{1}$ Programa de Pós-Graduação em Saúde Coletiva. Universidade Federal de São Paulo.

${ }^{2}$ Programa de Pós-Graduação em Gestão da Clínica. Universidade Federal de São Carlos. 


\section{INTRODUÇÃO}

Nos últimos anos, a política de saúde tem sido focada na garantia da atenção à saúde em uma dimensão humanista e de amplitude integral, de modo a assegurar o pleno gozo do direito e a construção de um sistema de saúde que a reconheça como direito de cidadania e dever do Estado e que valorize a dimensão subjetiva dos sujeitos nos vários níveis de atenção. Como estratégias assumidas para essa política nacional de humanização, política transversal, norteadora das práticas de gestão e atenção em todas as esferas do Sistema Único de Saúde (SUS), o Ministério da Saúde incorporou os dispositivos/ conceitos de apoio matricial e equipe de referência.

Esses dispositivos/conceitos constituem elementos político-assistenciais tanto da Política Nacional de Humanização (PNH) - também conhecida como HumanizaSUS ${ }^{1,2}$ - quanto da política de Saúde Mental e da Estratégia de Atenção Básica/Saúde da Família³. A organização dos Núcleos de Apoio à Saúde da Família (Nasf) também se pautou nessa lógica de gestão e produção do cuidado ${ }^{4}$. O principal objetivo dos Nasf tem sido apoiar a inserção da Estratégia Saúde da Família (ESF) na rede de serviços, além de ampliar a abrangência das ações da Atenção Básica, e aumentar a resolutividade dela, reforçando os processos de territorialização e regionalização em saúde ${ }^{5}$.

Apoio matricial e equipes de referência são dispositivos-conceitos ${ }^{6,7}$. A meta do apoio matricial é construir um modelo de gestão como alternativa operacional ao modelo taylorista, que assegure a produção qualificada de saúde e garanta a própria sobrevivência do SUS, além da realização dos próprios trabalhadores ${ }^{7}$. Em conjunto com a implantação de equipes de referência, temos uma lógica que preza o trabalho em equipes multiprofissionais, centrada nas necessidades do usuário, contrária à lógica hegemônica que traz a atenção centrada na assistência curativa e nos procedimentos.

A adoção dessas estratégias combinadas visa desviar-se dos recortes das divisões de saberes, agrupados por núcleo profissional; e estimular a autonomia dos profissionais e, ao mesmo, tempo o sentido de rede de compromisso, influenciando diretamente o princípio da integralidade da atenção.

Esse conjunto de estratégias tem como objetivo assegurar um diálogo entre usuários e técnicos, diminuindo em alguns graus a alienação e a burocratização entre os servidores, e, dessa forma, horizontalizar as relações de trabalho dentro dos serviços de saúde, a fim de que o processo de trabalho seja menos compartimentado, segmentado, visando à construção de projetos terapêuticos mais compartilhados.

Desse modo, contribuiria motivando-os a ampliar sua capacidade de reflexão e autoestima ${ }^{7}$, levando à construção de processos de produção do cuidado pautados na cogestão, isto é, conduzida por coletivos organizados, que utilizam conceitos dos campos da política, planejamento, análise institucional e educação continuada, atuando em espaços coletivos ${ }^{8,9}$.

Esse novo modo de fazer gestão propõe estimular o estabelecimento de uma nova lógica de trabalho pelo compartilhamento das ações, conhecimentos e técnicas entre os trabalhadores, e intenciona reorganizar os serviços na lógica da Integralidade. Também reafirma a prática clínica dos profissionais de forma ampliada, em que as ações de saúde são construídas a partir das necessidades de saúde do usuário, e não só do conhecimento técnico específico de cada núcleo profissional, o que limita a escuta dessas necessidades e a oferta de ações em relação a elas. Fica claro que se trata de uma lógica de trabalho em consolidação, mas com grande potencial de provocar modificações na organização dos serviços e na própria estrutura do sistema de saúde 6 .

A clínica ampliada busca integrar 
as várias abordagens, possibilitando um enfrentamento mais direto do trabalho em saúde, colocando em discussão a fragmentação do processo de trabalho, melhorando a compreensão do processo saúde-doença, trabalhando a responsabilização, construindo diagnósticos e terapêuticas compartilhados. Tem como meta a transformação do trabalho, inclusive da própria clínica, que deve transcender a mera prescrição medicamentosa, incentivada a partir da discussão da gestão compartilhada por vários saberes em diálogo.

A clínica ampliada objetiva, portanto, ser ferramenta de articulação e inclusão dos diferentes enfoques e disciplinas, a fim de que o trabalhador veja além da fragmentação de serviços e cuidados. Ainda que em determinado momento possa existir a prioridade de enfoque em um único problema, isso não deve significar a negação dos outros aspectos do indivíduo na sua complexidade e singularidade.

Tal modo de gestão objetiva centralmente ampliar a capacidade de direção dos grupos, aumentando também a capacidade de análise e operacionalização sobre o mundo - práxis - baseado na análise e intervenção. Opera com o conceito ampliado de gestão: função gerencial, política, pedagógica e terapêutica. Nessa proposta, atuará um apoiador que se compromete com as equipes, ajuda-as na construção de espaços coletivos; e, nesses espaços, o grupo todo analisa, define tarefas e elabora projetos de intervenção. Enfim, trabalha com coletivos em processo de organização, e pressupõe trabalho em grupo, espaços coletivos e gestão compartilhada, além de autonomia profissional e definição de responsabilidade clínica ${ }^{8,9}$.

Sob esse enfoque, o papel do apoio é fazer articulação entre os diferentes e vários atores envolvidos no cuidado, sejam eles integrantes dos serviços de saúde ou não, com abordagens intersetoriais. O apoio matricial deve se concretizar por meio da construção de um projeto terapêutico integrado, ou seja, como resultado de uma articulação entre equipe de referência e equipe de apoio. Enquanto tal, o projeto deve desenvolver-se em três planos: intervenções conjuntas entre as equipes; atenção específica ao núcleo de saber do apoiador; e compartilhamento de responsabilidade entre equipe de referência e de apoio.
O apoio matricial como eixo transversal da política de humanização é potente para a produção de novos modos de operar e deve estimular uma nova concepção de trabalho em saúde; também é potente no processo de ressignificar a intervenção dos profissionais e o saber clínico, de modo que possa haver maiores responsabilidades na atenção individual e coletiva de forma comprometida e na articulação do sistema de saúde. É plausível, no entanto, que o apoio se restrinja à troca de conhecimento e orientações; permanecendo, contudo, o caso sob cuidado da equipe de referência ${ }^{6,7}$. Segundo as diretrizes da $\mathrm{PNH}$, a relevância dessa lógica gestão do trabalho se dá no resgate do compromisso com os sujeitos, e a complexidade do processo saúde/ doença/cuidado, qualificando o processo de trabalho ${ }^{2}$.

Este estudo tem como finalidade verificar a experiência concreta, e singular, das práticas de apoio matricial. Volta-se, portanto, para a participação do profissional fisioterapeuta inserido como apoiador em equipe multiprofissional de saúde. Visa contribuir para o debate das experiências do apoio matricial, estabelecendo uma relação dialógica com a teoria, ao apresentar e discutir elementos contextuais da atuação do profissional fisioterapeuta na Atenção Básica como apoiador matricial: identificar a demanda, os motivos de procura pelos serviços de saúde referidos, os encaminhamentos (referência e contrarreferência) e a relação existente entre o profissional apoiador e o processo de trabalho da equipe.

A investigação aconteceu na Rede de Atenção Básica de Saúde de um município do interior de São Paulo a partir do apoio matricial a duas equipes de Saúde da Família. O município em questão está estruturando sua Rede de Saúde-Escola, implantando reformulações no processo de trabalho, adotando as premissas da $\mathrm{PNH}$, e novos dispositivos de educação e formação, como o programa de Residência Multiprofissional em Saúde da Família e Comunidade. A Residência é um modelo de formação profissional em serviço para o SUS que pretende formar profissionais que trabalhem de maneira interdisciplinar, a partir da proposta de apoio matricial, preconizado pelo Nasf. $\frac{3}{\text { Bragagnolo e Aciole }}$ 


\section{MÉTODOS}

A coleta de dados foi realizada com todos os usuários que procuraram atendimento referenciado no período de 23 de setembro a 23 de novembro de 2014, totalizando 22 usuários cadastrados em duas equipes de Saúde da Família do município de São Carlos.

Os usuários participantes foram encaminhados para avaliação fisioterápica ou procuraram atenção desse profissional espontaneamente (demanda espontânea). $\mathrm{O}$ estudo teve início após o parecer favorável do Comitê de Ética em Pesquisa da Universidade Federal de São Carlos (Parecer CEP 254); e os usuários foram informados sobre os objetivos e procedimentos do estudo, por meio de exposição oral e escrita. Aqueles que se voluntariaram assinaram o Termo de Consentimento Livre e Esclarecido, de acordo com a Resolução ${ }^{\circ}$ 196/96 do Conselho Nacional de Saúde.

Na primeira etapa, após a avaliação inicial do usuário, foi aplicado pela apoiadora-fisioterapeuta, e coautora deste artigo, um questionário estruturado, para registro dos dados pessoais, sociodemográficos e clínicos. Após o atendimento, a segunda etapa consistiu em análise do prontuário sobre as ações e encaminhamentos relativos à fisioterapeuta apoiadora, relacionados com os casos.

A análise documental e dos dados referentes às ações da fisioterapeuta apoiadora e encaminhamentos dos casos teve como eixo norteador os conceitos de integralidade ${ }^{10,11}$, que rege a $\mathrm{PNH}^{2}$, e de apoio matricial $^{6,7}$, que são meios da concretização desse ideal. A análise dos dados referentes ao estudo do perfil clínico dos usuários, origem dos encaminhamentos e ações realizadas pelo fisioterapeuta foi feita utilizando técnicas descritivas.

\section{RESULTADOS E DISCUSSÃO}

Visando dar sistematicidade à discussão, os resultados foram agrupados em dois aspectos centrais: primeiro, a caracterização da demanda e dos motivos da procura pelo serviço; segundo, com as consequências decorrentes para o processo de trabalho em que se situa a participação do apoio matricial.

\section{Perfil dos usuários atendidos $e$ demanda para o trabalho em Saúde}

A demanda relativa ao acionamento do fisioterapeuta apoiador na Unidade de Saúde da Família (USF), em sua maioria, foi constituída de mulheres adultas, de idade entre 41 e 59 anos (Tabela 1). O predomínio de mulheres atendidas pelos serviços de saúde é fato relatado na literatura $^{12}$.

Tabela 1. Distribuição dos usuários atendidos pelo fisioterapeuta apoiador da USF segundo gênero e faixa etária

\begin{tabular}{|c|c|c|c|c|c|c|}
\hline \multirow{2}{*}{ Faixa etária } & \multicolumn{2}{|c|}{ Masculino } & \multicolumn{2}{|c|}{ Feminino } & \multicolumn{2}{|c|}{ Total } \\
\hline & $\mathbf{n}$ & $\%$ & $\mathbf{n}$ & $\%$ & $\mathbf{n}$ & $\%$ \\
\hline 0 a 19 anos & 1 & 4.54 & 2 & 9.09 & 3 & 13.63 \\
\hline 20 a 39 anos & 3 & 13.63 & 2 & 9.09 & 3 & 13.63 \\
\hline 40 a 59 anos & 3 & 13.63 & 5 & 22.72 & 8 & 36.36 \\
\hline 60 a 79 anos & 0 & 0 & 4 & 18.18 & 4 & 18.18 \\
\hline+ de 80 anos & 1 & 4.54 & 1 & 4.54 & 2 & 9.09 \\
\hline Total & 8 & 36.36 & 14 & 63.63 & 22 & 100 \\
\hline
\end{tabular}

Fonte: elaboração própria. 
Entre as demandas apresentadas, podemos enumerar casos de Acidente Vascular Cerebral (AVC), Tuberculose (Tb), dificuldades na marcha, cuidado a usuários acamados, procura por encaminhamento para o nível especializado de usuários com queixas de atraso no Desenvolvimento Neuropsicomotor (DNPM) e alteração postural (escoliose). Porém, as queixas relativas à dor musculoesquelética foram predominantes, alcançando $68,1 \%$ dos casos (Tabela 2).

O predomínio desse motivo de procura, considerado em conjunto com a maior demanda de pacientes do sexo feminino, pode ser justificado pelo papel e pela posição da mulher na sociedade ao longo do processo histórico. Estas são mulheres que enfrentam dupla jornada de trabalho e que sofrem o desgaste dos trabalhos manuais, relacionados com as atividades do trabalho doméstico e profissional. Comumente de baixa conotação econômica, ele é tido como trabalho improdutivo, pois gera baixo retorno monetário ${ }^{13}$. Não obstante, essa é apenas uma das dimensões desse sofrimento, a ser pensada nos vários contornos da integralidade do cuidado.

De todos os usuários atendidos, $36,35 \%$ eram trabalhadores informais, enquanto $18,18 \%$ afirmaram ter vínculo empregatício; e a função ocupada por eles era de operário. Aposentados e pensionista somaram $31,81 \%$, enquanto estudantes ou incapazes sem atividade, $13,63 \%$.

Tabela 2. Distribuição dos usuários atendidos pelo fisioterapeuta apoiador segundo motivo da consulta e gênero

\begin{tabular}{lcccccc}
\hline \multirow{2}{*}{ Motivo da consulta } & \multicolumn{2}{c}{ Masculino } & \multicolumn{2}{c}{ Feminino } & \multicolumn{2}{c}{ Total } \\
\cline { 2 - 7 } & $\mathbf{n}$ & $\%$ & $\mathbf{n}$ & $\%$ & $\mathbf{n}$ & $\%$ \\
\hline Dor * & 5 & 22.72 & 10 & 45.45 & 15 & 68.18 \\
Tuberculose & 1 & 4.54 & 0 & 0 & 1 & 4.54 \\
Escoliose & 0 & 0 & 1 & 4.54 & 1 & 4.54 \\
Trauma/Dificuldade na marcha & 0 & 0 & 2 & 9.09 & 2 & 9.09 \\
Atraso no Desenvolvimento Neuropsicomotor & 1 & 4.54 & 0 & 0 & 1 & 4.54 \\
Acamado/Acidente Vascular Cerebral & 1 & 4.54 & 1 & 4.54 & 2 & 9.09 \\
\hline Total & $\mathbf{8}$ & $\mathbf{3 6 . 3 6}$ & $\mathbf{1 4}$ & $\mathbf{6 3 . 6 3}$ & $\mathbf{2 2}$ & $\mathbf{1 0 0}$ \\
* (origem osteomuscular e tec. conjuntivo) & & & & & &
\end{tabular}

Fonte: elaboração própria.

A distribuição dos usuários atendidos segundo o motivo do atendimento pode dar indícios da conformação da demanda que cerca a USF, assim como do território adscrito, que se mostra composto, em sua maioria, por adultos, trabalhadores informais. Ademais, também corrobora estudos sobre a importante prevalência da dor musculoesquelética ${ }^{14,15}$, o que se reflete na Atenção Básica, porta de entrada do sistema de saúde. 
Isso também pode sugerir que os profissionais envolvidos não conhecem outras possibilidades de atuação do fisioterapeuta, e concebem que esse profissional lide somente com dores ou fraturas, e desconhecem outros campos de atuação ou formas de intervir. Mais distante ainda deste senso comum, pode ser a atuação do fisioterapeuta inserido na reorientação do modo de produzir saúde, na ressignificação das formas de desenvolver o cuidado individual e coletivo, que é o que se espera de um apoiador matricial.

Entre os usuários participantes do estudo, isto é, usuários com queixas de dor musculoesquelética, o tempo decorrido desde o início do sintoma, em sua maioria (60\%), não supera os seis meses (Tabela 3$)$, ou seja, ainda em estágio agudo ${ }^{16}$.

Tabela 3. Distribuição dos usuários atendidos pelo fisioterapeuta apoiador na USF segundo tempo decorrido de dor e gênero

\begin{tabular}{lcccccc}
\hline \multicolumn{1}{c}{ Tempo decorrido - dor } & \multicolumn{2}{c}{ Masculino } & \multicolumn{2}{c}{ Feminino } & \multicolumn{2}{c}{ Total } \\
\cline { 2 - 7 } & $\mathbf{n}$ & $\%$ & $\mathbf{n}$ & $\%$ & $\mathbf{n}$ & $\%$ \\
\hline Até 1 mês & 3 & 20.00 & 3 & 20.00 & 6 & 40.00 \\
2 meses até 6 meses & 0 & 0.00 & 3 & 20.00 & 3 & 20.00 \\
Mais de 6 meses & 2 & 13.33 & 4 & 26.66 & 6 & 40.00 \\
\hline Total & $\mathbf{5}$ & $\mathbf{3 3 . 3 3}$ & $\mathbf{1 0}$ & $\mathbf{6 6 . 6 6}$ & $\mathbf{1 5}$ & $\mathbf{1 0 0}$ \\
\hline
\end{tabular}

Fonte: elaboração própria. convencionais. Além disso, é a causa de incapacidades e inabilidades prolongadas ${ }^{15}$. Tais fatores podem justificar, por exemplo, que as políticas de saúde, como a $\mathrm{PNH}$ e a ESF, em suma, o próprio SUS, admitam a necessidade de novas tecnologias no cuidado para a dor, dado o seu caráter multifatorial.

A inaptidão do modelo biomédico para intervir nas condições de vida da população aponta que este deve dar espaço a novas tecnologias, como o vínculo, a clínica ampliada, o projeto terapêutico, a escuta qualificada e a corresponsabilização entre equipe e usuário para a intervenção em agravos em geral, especialmente na dor, a fim de que o profissional entenda que lugar a dor ocupa na vida do usuário. Assim, práticas que valorizam as relações intersubjetivas aproximam terapeuta e paciente no processo saúde/doença/ atenção $0^{2,13,18}$.

Essas tecnologias fazem parte do intento da Atenção Básica, e, por isso, ela precisa de habilidade para lidar com problemas diversos e dar resolutividade nas diferentes situações. É importante que a rede básica esteja preparada para enfrentar os desafios que batem à porta, como é o caso da dor. A Atenção Básica precisa estar articulada com o suporte do apoio técnico-pedagógico, que é uma das ferramentas, e pode potencializar suas ações.

\section{O processo de trabalho na USF o apoio matricial}

Esse grande número de queixas agudas indica uma inversão no uso ideal do sistema de saúde, em que se espera que queixas agudas sejam atendidas em unidades de urgência como é o caso dos Pronto Atendimentos, e não na Atenção Básica. Porém, existem muitas explicações para a escolha do serviço a ser utilizado pelo usuário, e tratam da subjetividade dos sujeitos envolvidos nessas relações, como o próprio vínculo entre usuário e trabalhadores, as experiências prévias do usuário com os serviços de saúde, e a distância da sua residência ${ }^{17}$.

A dor crônica também não pode ser ignorada: representa $40 \%$ dos casos de dor no presente estudo, tem etiologia incerta, e pode não desaparecer com o emprego dos procedimentos terapêuticos

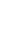


Tabela 4. Distribuição dos usuários atendidos pelo fisioterapeuta apoiador na USF segundo modo de encaminhamento e profissional que realizou este encaminhamento

\begin{tabular}{lccc}
\hline Profissional encaminhador & $\mathbf{n}$ & $\%$ & Modo como fez o encaminhamento \\
\hline Auxiliar de Enfermagem & 8 & 36.32 & Discussão informal \\
Agente Comunitário de Saúde & 3 & 13.63 & Discussão informal \\
Médico & 3 & 13.63 & Atendimento conjunto e bilhetes \\
Demanda espontânea para fisioterapia & 3 & 13.63 & \\
Enfermeiro & 2 & 9.09 & Discussão informal \\
Discussão de Caso & 2 & 9.09 & Discussão formal \\
Outro profissional da Matricial & 1 & 4.54 & Discussão informal \\
\hline Total & $\mathbf{2 2}$ & $\mathbf{1 0 0 . 0 0}$ & \\
\hline
\end{tabular}

* Os autores denominaram discussão informal como a solicitação de intervenções feita fora dos mecanismos formais estabelecidos de comunicação como Reunião de Equipe e Reuniões de discussão de Casos.

** Os autores denominaram discussão formal a solicitação ocorrida em espaços pré-estabelecidos para tais discussões, como reuniões de equipe e discussão de caso. Fonte: elaboração própria.

Os usuários encaminhados pelo profissional auxiliar de enfermagem $(36,32 \%)$ (demanda não programada ou espontânea) representam grande parte da demanda que chega para o acolhimento, e logo são referenciados para a avaliação do apoiador, por pedido verbal e informal. Diante de encaminhamentos realizados por vias informais, um dos questionamentos é se os profissionais que fizeram a referência ao apoiador matricial se deram conta de que esse modelo de gestão da clínica tem caráter transformador do processo de trabalho ou se é apenas um meio de conseguir ajuda para 'dar conta' da grande demanda. Esse jeito de fazer pode se tornar uma maneira que os profissionais encontram de burlar a formalidade das discussões em equipe.

Os encaminhamentos realizados pelos médicos ao apoiador matricial $(13,63 \%)$ aconteceram de duas formas: por meio de solicitação imediata de consulta conjunta e encaminhamento por bilhetes anexados aos prontuários. Enquanto a consulta conjunta é um espaço rico para trocas de saberes e pactuações, encaminhamentos por anotações anexadas aos prontuários com solicitação de avaliação não são coerentes com o apoio matricial, pois é preciso que ambos se responsabilizem sobre o cuidado. Nesse segundo caso, o responsável por guardar os prontuários no arquivo transmitia os bilhetes ao fisioterapeuta. Dessa maneira, os bilhetes se perdem facilmente; a fragmentação do cuidado se torna inevitável. Outrossim, também se trata de uma maneira de burlar a formalidade dos espaços de discussões.
A demanda espontânea apresentada (13.63\%) se constituiu de usuários em tratamento no setor especializado que precisavam 'renovar a guia', procedimento burocrático do sistema: atualmente, o encaminhamento para o nível especializado da atenção se faz por guias SADT (Serviços Auxiliares de Diagnóstico e Terapia). Diferentes procedimentos como exames e terapias utilizam as SADT; no caso do encaminhamento ao setor ambulatorial de fisioterapia, uma guia SADT garante dez sessões de atendimento especializado. Assim, a cada dez sessões, o usuário precisa renovar as guias com médico ou fisioterapeuta da Atenção Básica para continuar o tratamento ambulatorial. Isso ocorre com a justificativa de que o pagamento desses procedimentos ao setor especializado se dá pela apresentação dessas guias; porém, essa burocracia se concretiza em uma desarticulação e fragmentação da rede que se reflete no cuidado.

Uma parcela menor dos casos foi encaminhada por discussão formal $(9.09 \%)$, ou seja, os espaços formais de discussão foram menos utilizados para acionar o apoiador fisioterapeuta. Esse baixo número de encaminhamentos formais pode demonstrar mudanças ainda muito tímidas no modo de produzir saúde, ou mesmo que os encontros periódicos entre os trabalhadores não sejam suficientes.

Outro fator que deve ser considerado é que outras discussões tomaram esse espaço, como a presença da psiquiatra somente nos horários das discussões de caso, o que concentra as discussões 
de caso no âmbito da Saúde Mental. que representa demanda importante e talvez priorizada pela equipe. Ainda podemos considerar que as relações e as subjetividades interferem na atuação dos diferentes atores nesses espaços.

Sobre a conduta tomada pelo apoiador fisioterapeuta, grande parte delas foram atendimentos pontuais com recursos terapêuticos $(40,90 \%)$; seguido por avaliação e encaminhamento ao setor ambulatorial (27,27\%); em seguida, atendimento conjunto com profissional da equipe referência, com orientações para decisões sobre encaminhamento ao nível especializado de atenção (18,18\%); e, por fim, a avaliação e o acompanhamento longitudinal do caso (13,63\%), sempre pautados na educação em saúde, tendo como meta o desenvolvimento da autonomia do usuário (Tabela 5).

Tabela 5. Conduta adotada pelo profissional fisioterapeuta apoiador mediante possibilidades do Apoio Matricial

\begin{tabular}{|c|c|c|}
\hline Conduta & $\mathrm{n}$ & $\%$ \\
\hline $\begin{array}{l}\text { Atendimento pontual com recursos terapêuticos e orientações ao usuário e ou } \\
\text { cuidador/ Educação em Saúde }\end{array}$ & 9 & 40.90 \\
\hline Avaliação, orientações e encaminhamento ao setor ambulatorial & 6 & 27.27 \\
\hline $\begin{array}{l}\text { Atendimento conjunto com profissional da referência, com orientações para decisões } \\
\text { sobre encaminhamento }\end{array}$ & 4 & 18.18 \\
\hline Avaliação, orientações ao gestor do cuidado, cuidador, acompanhamento do caso & 3 & 13.63 \\
\hline Total & 22 & 100 \\
\hline
\end{tabular}

Fonte: elaboração própria. personalizados, contato pessoal telefônico ou virtual, não somente encaminhamento impresso, burocratizado em prazos, fluxos e dureza operaciona ${ }^{16}$.

Outro fato importante é que essa informalidade, obviamente, facilita o encontro entre os profissionais, e essas 'conversas de corredor' representam uma rede de comunicação entre eles, tomando um caráter de espaço aberto como o das praças. A praça é constituída de encontros, é um lugar público ocupado por diferentes atores que instituem o uso desse lugar sem a obrigatoriedade de ter que realizar uma função única e específica, pois várias estão em produção, em diversos coletivos. Nesses coletivos, vão-se entremeando uma funcionalidade instituída e uma missão: a produção de saúde. Ou seja, os atores sociais/sujeitos operam a produção do lugar e o fazem por interação contínua e recíproca $^{19}$.

Em outras palavras, o modo de operar o processo de trabalho se dá pelo acordo realizado entre esses profissionais e os usuários em ato; um momento singular, no qual se entremeiam interesses privados tornados públicos, isto é, submetidos a um coletivo de trabalho que carrega seus próprios interesses corporativos e, portanto, particulares; imersos na solidão profissional em que precisam negociar um agir conjunto no oceano coletivo, público, de equipe ${ }^{20}$.

Ainda que seja um espaço muito utilizado e possa ser tornado educativo e significativo para a construção de uma prática dialógica, o caráter de informalidade nos parece ser um óbice importante à ideia de corresponsabilização entre os serviços e profissionais, e de articulação dos atores pela referência e contrarreferência, possibilitando o vínculo terapêutico, aproximando o usuário do seu tratamento e das equipes.

Do mesmo modo, podem tornar invisível o trabalho do apoiador, especialmente se somado ao fato de este não se dedicar exclusivamente à clínica (leia-se, ter uma agenda disponível para atendimentos individuais para ajudar a dar conta da demanda). O predomínio das atividades assistencialistas na rotina do apoiador é 
justificado por vários fatores, dos quais destacamos: o fato de ser mais um profissional de saúde, o processo de trabalho da unidade está voltado para atenção à demanda; a expectativa da equipe no desempenho do apoiador e seu papel; as subjetividades dos atores envolvidos na unidade de saúde.

Afinal, o trabalho do apoiador matricial deve consistir na articulação de atores institucionais e na formação de rede, e não apenas na produção de consultas. Por ser, muitas vezes, uma conversa a dois, a informalidade acaba por excluir os demais profissionais envolvidos no cuidado, na comunicação e no processo de trabalho, afetando o alcance da integralidade, ao gerar sobreposição ou compartimentação das ações. Por isso, julgamos importante que essas discussões caminhem para os espaços privilegiados de trocas entre toda a equipe reunida. Ressalve-se que estas não são as únicas intervenções possíveis do apoiador inserido em uma equipe, havendo outros elementos do cardápio, como os espaços pedagógicos de educação permanente, aos quais o estudo não se propôs, ou não pôde observar, na unidade em questão. O foco definido cingiu-se ao atendimento à demanda assistencial.

As equipes de referência manifestaram, por exemplo, a expectativa de que o apoio se resumisse em um reforço assistencial na atenção direta aos usuários, para ajudar a dar conta da grande demanda, em uma tendência a se desresponsabilizar do enfrentamento de seus problemas. Esta compreensão do matriciamento, reduzido a apoio assistencial, não é, contudo, privilégio desse município ou dessas equipes, ocorrendo em outras experiências pelo País, como é caso relatado no Nordeste ${ }^{21}$.

Acerca dos encaminhamentos para a atenção especializada, estes representam $27,27 \%$ dos casos, e são relativos aos usuários que necessitavam de atendimento compatível com o nível especializado de atenção, bem como dos usuários em acompanhamento no serviço especializado que necessitavam 'renovar suas guias' (os encaminhamentos SADT), como citado anteriormente. Contudo, até mesmo os casos de encaminhamento contaram com a avaliação e práticas pedagógicas.

A comunicação dialógica orientou as ações pedagógicas aqui relatadas, segundo a lógica da educação em saúde, cuja construção de saberes sobre o processo saúde/doença/cuidado capacite os indivíduos a decidir quais as estratégias mais apropriadas para promover, manter e recuperar sua saúde. Assim, o objetivo não é de informar, mas de transformar saberes e valores existentes, na direção do desenvolvimento da autonomia e da responsabilidade dos indivíduos no cuidado com a saúde, com práticas educativas emancipatórias ${ }^{22}$.

A decisão sobre o encaminhamento de um caso ao serviço especializado de atenção ou mesmo ao apoiador matricial, segundo a lógica do cuidado multiprofissional centrado nas necessidades do usuário, seria tomada de maneira interativa entre equipe de referência e profissional-apoiador6; e isso implica discussão do caso, o que aconteceu em 18,18\% dos casos já nos momentos de atendimentos conjuntos.

Essa discussão pode acontecer em uma consulta conjunta, pois os espaços de intervenções conjuntas têm grande potencial para serem espaços pedagógicos, tanto para usuários como para profissionais, acerca das condutas terapêuticas. Esses momentos conjuntos são espaços de pactuação entre profissional e usuário; além disso, são momentos em que os profissionais estabelecem critérios para encaminhamento ao nível especializado da atenção, critérios que serão utilizados em outros momentos para outros casos semelhantes.

Ainda propondo uma intervenção compromissada com as práticas e as construções coletivas, em $13,63 \%$ dos casos, a conduta foi baseada na avaliação do usuário, orientação do gestor do cuidado e cuidador, e acompanhamento longitudinal do caso. Com a avaliação e a orientação do gestor do cuidado e cuidador (quando é o caso), o apoiador fisioterapeuta atende às expectativas de atuação relativa ao núcleo profissional que a equipe, usuário e família têm.

Assim, o apoiador fisioterapeuta também desempenha explicitamente o caráter de 'apoio técnico-pedagógico' previsto pelo apoio matricial. É importante ressaltar que o acompanhamento longitudinal deve reforçar que o vínculo seja realmente estreitado com o profissional da equipe de referência, colaborando para 
uma construção de um novo processo de trabalho em saúde baseado na responsabilização entre os atores.

\section{CONCLUSÕES}

A análise da experiência específica das práticas de apoio matricial em questão revela que as práticas ainda estão em consolidação no contexto em que ocorreu o estudo. Poucos relatos de experiência de apoio matricial foram publicados; os que o foram, em sua maioria, são relativos às experiências na Saúde Mental, o que dificulta visualizar quantitativa e qualitativamente a implantação da proposta em outros setores específicos e com características diversas.

Por ser uma estratégia recente no SUS, ainda existem equívocos sobre o papel do apoiador, que precisa lidar com a expectativa das equipes de referência pelo atendimento clínico. É importante que o trabalho do apoiador matricial não se perca nessas expectativas da equipe, mas também não deve se desvincular das suas necessidades. Como já observado, o apoio matricial ainda não atinge a articulação entre equipe de referência e apoio matricial da forma sugerida pelas políticas de saúde. Nesse olhar sobre uma experiência local, revelam-se obstáculos ao quesito da corresponsabilização do cuidado.

O desafio é utilizar ferramentas potencializadoras do cuidado que o apoio matricial pode trazer, como a educação em saúde, a educação permanente, a multiplicidade de olhares para as discussões de caso e reuniões de equipe, nas construções de projetos terapêuticos, entre outros, sempre a partir da corresponsabilização do cuidado.

Como observado neste relato, a equipe de referência pode, por vezes, dispensar a longitudinalidade do cuidado dos usuários pela sobrecarga da demanda, deixando em segundo plano a integralidade do cuidado. Porém, os trabalhadores e os gestores locais podem, e devem, elaborar estratégias de atuação capazes de atender às necessidades de saúde das localidades. Além disso, o trabalho coeso de todos os atores que compõem essa perspectiva interdisciplinar é necessário, pois a integralidade não se concretiza sem interdisciplinaridade - e a sutileza do apoio matricial na construção do cuidado integral não deve se encerrar na produção de atos profissionais.

\section{REFERÊNCIAS}

1.Brasil. Ministério da Saúde. Secretaria de Atenção à Saúde. Clínica Ampliada e Compartilhada: HumanizaSUS. Brasília: SAS; 2009.

2.Brasil. Ministério da Saúde. Secretaria de Atenção à Saúde. Política nacional de humanização: HumanizaSUS. Documento Base. 3. ed. Brasília: SAS; 2006.

3.Brasil. Ministério da Saúde. Secretaria de Atenção à Saúde. A política de Saúde Mental do Ministério da Saúde. Brasília: SAS; 2004.

4.Brasil. Ministério da Saúde. Gabinete do Ministro. Portaria n ${ }^{\circ} 154$, de 24 de janeiro de 2008. Cria os Núcleos de Apoio à Saúde da Família - NASF. Diário Oficial da União [Internet]. 2008 [acessado 2011 set 10]; 4 mar. Disponível em: http://dtr2004. saude.gov.br/dab/nasf.php

5.Brasil. Ministério da Saúde. Secretaria de Atenção à Saúde. Departamento de Atenção Básica. Cadernos de Atenção Básica n. 27. Diretrizes do NASF. Brasília: SAS; 2009.

6.Campos GSW, Domitti AC. Apoio Matricial e equipe de referência: uma metodologia de gestão do trabalho interdisciplinar em saúde. Cad Saúde Pública. 2007;23(2):399-407.

7.Campos GWS. Equipes de referência e apoio especializado matricial: um ensaio sobre a reorganização do trabalho em 
saúde. Ciênc Saúde Coletiva [Internet]. 15.Teixeira MJ, Marcon RM, Rocha RO. 1999 [acessado 2011 set 10];4(2):387-399. Epidemiologia da dor. In: Teixeira MJ, Disponível em: http:/www.scielo.br/pdf/ Figueiró JAB, organizadores. Dor: epicsc/v4n2/7121.pdf

8.Campos GWS. Um método para análise e cogestão de coletivos. São Paulo: Hucitec; 2000.

9.Campos GSW. O Anti-Taylor: sobre a invenção de um método para co-governar instituições produzindo liberdade e compromisso. Cad Saúde Pública [Internet]. 1998 [acessado 2011 set 10];14(4):879896. Disponível em: http://www.scielo. br/pdf/csp/v14n4/0080.pdf

10.Camargo Júnior KR. Um ensaio sobre a (in)definição da integralidade. In: Pinheiro R, Mattos R, organizadores. Construção da integralidade: cotidiano, saberes e práticas em saúde. Rio de Janeiro: UERJ, IMS; ABRASCO; 2003. p 35-44.

11.Mattos R. Os sentidos da integralidade: algumas reflexões acerca de valores que merecem ser defendidos. In: Pinheiro R, Mattos R, organizadores. Os sentidos da integralidade na atenção e no cuidado à saúde. Rio de Janeiro: UERJ, IMS, ABRASCO; 2001. p 39-64.

12.Ibañez N, Rocha JSY, Castro PC, Ribeiro MCSA, Forster AC, Novaes MHD, et al. Avaliação do desempenho da atenção básica no Estado de São Paulo. Ciênc Saúde Coletiva [Internet]. 2006 [acessado 2011 mar 12];11(3):567-580. Disponível em: http://www.scielo.br/pdf/ csc/v11n3/30983.pdf

13.Bedrikow R. Dor crônica em mulheres: uma reflexão sobre a clínica [dissertação]. Campinas (SP): Faculdade de Ciências Médicas, Universidade de Campinas; 2008.

14.Cordeiro Q, Khouri ME, Corbett CE. Dor musculoesquelética na atenção primária à saúde em uma cidade do Vale do Mucuri, nordeste de Minas Gerais. Acta Fisiátrica [Internet]. 2008 [acessado 2011 mar 18];15(4):241244. Disponível em: http:/www.actafisiatrica.org.br/v1/controle/secure/ Arquivos/AnexosArtigos/3473DECCCB0509FB264818A7512A8B9B acta_15_04_241-244.pdf $\frac{11}{\text { Bragagnolo e Aciole }}$ demiologia, fisiopatologia, avaliação, síndromes dolorosas e tratamento. São Paulo: Moreira Júnior; 2001. p.1-7.

16.Merskey NB. Classification of chronic pain: descriptions of chronic pain syndromes and definitions of pain terms prepared by the International Association for the Study of Pain. 2nd ed. Seattle: IASP Press; 1994.

17.Traverso-Yépez M, Morais NA. Reivindicando a subjetividade dos usuários da rede básica de saúde: para uma humanização do atendimento. Cad Saúde Pública [Internet]. 2004 [acessado $2011 \mathrm{mar}$ 12];20(1):80-88. Disponível em: http:// www.scielo.br/pdf/csp/v20n1/22.pdf

18.Lima MAG, Trad LAB. A dor crônica sob o olhar médico: modelo biomédico e prática clínica. Cad Saúde Pública [Internet]. 2007 [acessado 2011 mar 12];23(11):1178-1192. Disponível em: http://www.scielosp.org/pdf/csp/ v23n11/14.pdf

19.Merhy EE. Público e privado: entre aparelhos, rodas e praças. In: Aciole GG. A Saúde no Brasil: cartografias do Público e do Privado. São Paulo: Hucitec; 2006. p. 9-15.

20.Aciole GG. A Saúde no Brasil: cartografias do Público e do Privado. São Paulo: Hucitec; 2006.

21.Dimenstein M, Severo AK, Brito M, Pimenta AL, Medeiros V, Bezerra E. O apoio matricial em Unidades de Saúde da Família: experimentando inovações em saúde mental. Saúde Soc [Internet]. 2009 [acessado 2011 mar 15];18(1):87-99. Disponível em: http://www.scielo.br/pdf/sausoc/v18n1/07.pdf

22.Alves VS. Um modelo de educação em saúde para o programa saúde da família: pela integralidade da atenção e reorientação do modelo assistencial. Interface (Botucatu) [Internet]. 2005 [acessado 2011 mar 18];9(16):39-52. Disponível em: http://www.scielo.br/pdf/icse/v9n16/ v9n16a04.pdf

Recebido: 27/05/2019 Aprovado: 29/04/2021 